\title{
Modulation of the mesospheric semiannual oscillation by the quasibiennial oscillation
}

\author{
Rolando R. Garcia and Fabrizio Sassi
}

National Center for Atmospheric Research, Boulder, Colorado, U.S.A.

(Received August 4, 1998; Revised January 25, 1999; Accepted February 16, 1999)

\begin{abstract}
Recent satellite and radar observations suggest that the semiannual oscillation (SAO) in the mesosphere is modulated by the stratospheric quasibiennial oscillation $(\mathrm{QBO})$. The modulation is only apparent during the SAO easterly phase, which is considerably stronger when QBO winds are westerly than when they are easterly. We use an equatorial beta-plane model to demonstrate how such a modulation could come about through selective damping of the equatorial wave spectrum excited by deep convection. The waves affected most strongly are easterly inertia-gravity waves of phase speeds slower than $\sim-40 \mathrm{~m} \mathrm{~s}^{-1}$. This is close to the zonal wind speed during the easterly phase of the QBO ( -30 to $-35 \mathrm{~m} \mathrm{~s}^{-1}$ ), so the waves suffer strong thermal damping or even absorption as they propagate through the stratosphere. Because these waves are important for driving the easterly phase of the mesopause SAO in the model, that phase is weaker when the stratospheric QBO winds are easterly. A similar modulation of the westerly phase of the SAO does not occur for two reasons: (1) QBO westerlies are only half as strong as QBO easterlies, and (2) much of the driving of the westerly phase of the SAO is accomplished by Kelvin waves of phase speed $\sim 40-60 \mathrm{~m} \mathrm{~s}^{-1}$. As a consequence, the QBO winds have negligible influence on the vertical propagation of waves with westerly phase velocity and hence on the westerly phase of the modeled SAO.
\end{abstract}

\section{Introduction}

Although the semiannual oscillation (SAO) was first described over thirty years ago (Reed, 1962, 1966), observations of its mesospheric component have been sparse until recently, when satellite and radar measurements have provided more or less continuous data over a period of a few years (see Garcia et al., 1997, for a review). One of the more interesting features of the new observations is the presence of an apparent modulation of the easterly ${ }^{1}$ phase of the mesospheric SAO by the stratospheric quasibiennial oscillation (QBO). The relationship was first described by Burrage et al. (1996) using data for 1992-1995 from the High Resolution Doppler Imager (HRDI) onboard the Upper Atmospheric Research Satellite.

The purpose of this study is to show how modulation of the mesopause SAO can come about through selective damping of the spectrum of vertically propagating waves forced by deep convection in the tropics. Sassi and Garcia (1997; hereafter SG) studied the excitation of equatorial waves by convective heating and showed that, using spatial and temporal distributions of the heating based on the work of Salby et al. (1991) and Bergman and Salby (1994), it is possible to model a realistic $\mathrm{SAO}$ in the middle atmosphere. The waves responsible for the SAO in the SG model include westerly Kelvin and inertia-gravity waves, and easterly inertia-gravity

\footnotetext{
${ }^{1}$ The terms "easterly" and "westerly" used throughout this paper are synonymous with "westward" and "eastward", respectively, which may be more familiar to some readers.

Copy right (C) The Society of Geomagnetism and Earth, Planetary and Space Sciences (SGEPSS); The Seismological Society of Japan; The Volcanological Society of Japan; The Geodetic Society of Japan; The Japanese Society for Planetary Sciences.
}

waves. The former drive the westerly phase of the SAO in the stratosphere and mesosphere, while the latter produce the easterly phase of the mesospheric SAO. The stratospheric easterly phase in the model is due to mean advection of easterly momentum by the meridional circulation which, being tied to the seasonal cycle, also sets the "clock" for the entire SAO and determines its semiannual period.

We begin by describing briefly the model of SG, and illustrating how the SAO is produced through driving of the zonal mean flow by the different eastward- and westwardpropagating waves. We then present a new simulation that includes specified QBO winds throughout the tropical stratosphere. The stratospheric winds are taken from the climatology compiled by the Free University of Berlin. The simulation is carried on for 3.75 years, which encompass one and a half cycles of the QBO. A modulation of the mesopause easterlies is evident in the simulation, with weaker winds occurring when the phase of the QBO is easterly. We compare the wave spectra at various altitudes during both phases of the QBO to elucidate how the QBO affects vertical propagation and hence driving of the mesospheric SAO.

\section{Model Description}

The model used in this study has been described in detail by SG; it will be summarized only briefly here. The momentum and temperature equations are solved on an equatorial beta-plane for the zonal-mean state and zonal wavenumbers $k=1-15$. The model is quasi-nonlinear in that wave-wave interactions are disregarded, but the waves do interact with the zonal-mean state through the convergence of heat and momentum fluxes. The governing equations are based on 
the formulation of Andrews et al. (1987). In the latitudeheight plane the model domain extends from the ground to $120 \mathrm{~km}$, with $1 \mathrm{~km}$ resolution, and between $\pm 40^{\circ}$, with approximately $3^{\circ}$ resolution. Dissipation poleward of $\pm 20^{\circ}$ is used to prevent reflection from the lateral boundaries.

The waves are forced by including a heating term on the right-hand side of the eddy thermodynamic equation. The forcing is intended to model the release of latent heat in organized deep convection; the spatial and temporal scales of the heating, as well as its time evolution, are modeled after the work of Salby et al. (1991), and Bergman and Salby (1994). These authors showed that the frequency spectrum of the heating, although predominantly red, contains nonnegligible power at relatively large wavenumbers and frequencies. There is, in particular, a concentration of power at the diurnal period, associated with diurnal fluctuations in convection over the tropical continents. Accordingly, the forcing in the model is represented as:

$$
\begin{aligned}
\mathcal{H}(x, y, t)= & S_{\mathrm{o}}(x, y) \cdot F(z) \cdot T_{\mathrm{o}}(t) \\
& +S_{\mathrm{c}}(x, y) \cdot F(z) \cdot T_{\mathrm{c}}(t)
\end{aligned}
$$

where $S_{\mathrm{o}}(x, y), S_{\mathrm{c}}(x, y)$ are the spatial distributions of the heating over oceanic and continental regions and $T_{\mathrm{o}}(t), T_{\mathrm{c}}(t)$ describe the corresponding time evolution. $F(z)$ is the vertical profile of the forcing, common to both oceanic and continental heating. $S_{\mathrm{o}}$ and $S_{\mathrm{c}}$ are modeled simply as Gaussian functions in $x$ and $y$, with appropriately chosen amplitudes and spatial scales (see $\mathrm{SG}$ ). $F(z)$ is a half-sinusoid, extending from the surface to $12 \mathrm{~km}$, with a maximum at $6 \mathrm{~km}$.

The temporal evolution of the heating has been specified such that its frequency spectrum reproduces the spectrum derived by Salby et al. (1991; their figure 9) from observations of the variability of brightness temperature associated with convective clouds. In order to capture in a simple fashion the "red" character of the frequency spectrum as well as the presence of strong diurnal peaks in continental convection, $T_{\mathrm{o}}$ and $T_{\mathrm{c}}$ are modeled as second-order autoregressive processes plus (in the case of continental heating) a deterministic function of diurnal period:

$$
\begin{gathered}
T_{\mathrm{o}}(t)=r \cdot T_{\mathrm{o}}(t-\Delta t)+\epsilon, \\
T_{\mathrm{c}}(t)=r \cdot T_{\mathrm{c}}(t-\Delta t)+\epsilon+\sqrt{2} \cos \Omega t
\end{gathered}
$$

where $r$ is the correlation coefficient ( $r=0.5$ at lag 1 day), $\Delta t$ is the time step, $\epsilon$ is a random process with variance $\left\langle\epsilon^{2}\right\rangle=1-r^{2}$, and $\Omega$ is the diurnal frequency $(\Omega=2 \pi / 86400$ $\left.\operatorname{rad~sec}^{-1}\right)$. The frequency spectra of $(2 \mathrm{a})-(2 \mathrm{~b})$ are consistent with those of Salby et al. (1991); details are given by SG.

\section{Results}

\subsection{Simulation without the QBO}

We reproduce here some of the salient results of the calculation of SG, wherein the QBO in zonal wind was not included. Figure 1 shows the seasonal evolution of the zonal wind in the middle atmosphere. A realistic SAO is present in both the stratosphere and mesosphere; the amplitude and phase of the semiannual harmonic (not shown, but see figure 3 of SG) compare well with those documented by Hirota (1978) from rocketsonde observations.

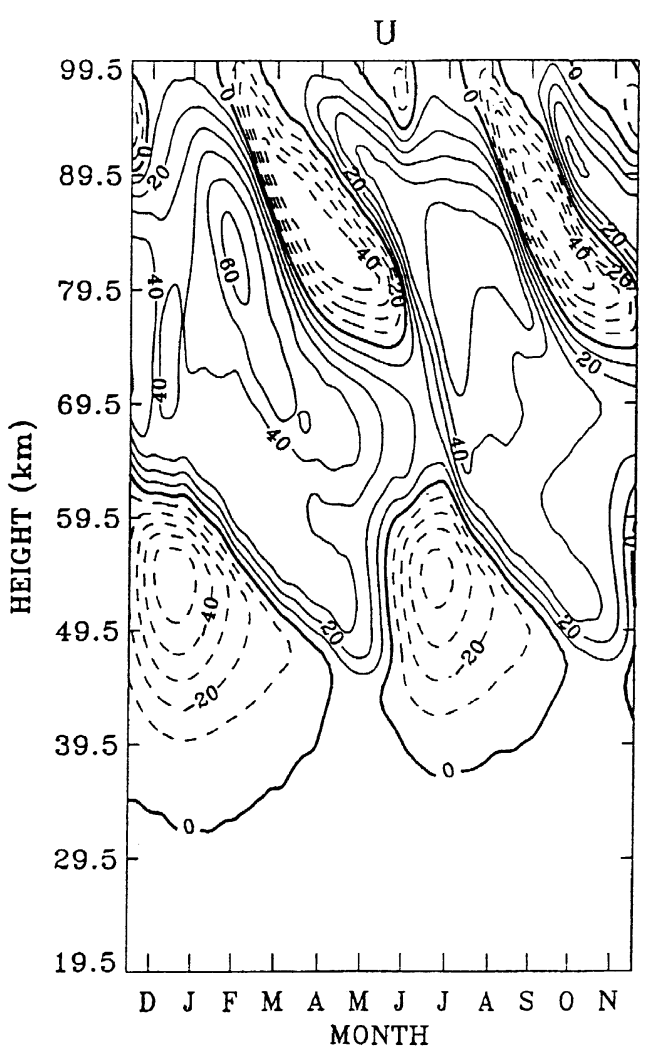

Fig. 1. The annual cycle of the zonal mean wind $\left(\mathrm{m} \mathrm{s}^{-1}\right)$ in the middle atmosphere in a run without the stratospheric QBO.

Figure 2 shows the wavenumber-seasonal evolution of wave driving near the stratopause and mesopause. At the stratopause the westerly phase of the SAO is driven by waves of planetary scale $(k=1-3)$, with a smaller but significant contribution from shorter waves. The stratopause easterly phase in our model is not wave driven; instead, it is the result of mean meridional advection of easterly momentum from the summer hemisphere. As noted earlier and discussed in detail by SG, this ties the stratopause easterly phase to the seasonal cycle and sets the semiannual "clock" for the rest of the SAO in the stratosphere and mesosphere. Near the mesopause, westerly wave driving is again provided by planetary scale waves, with significant contributions from higher wavenumbers. On the other hand, easterly wave driving is due almost exclusively to waves of zonal wavenumber $k \geq 7$.

Sassi and Garcia documented the nature of the waves that drive the simulated SAO. The westerly, planetary-scale waves are Kelvin waves. Their vertical wavenumber is determined by the vertical scale of the convective heating, which projects most efficiently upon waves of vertical wavelength twice the depth of the forcing (Holton, 1972, 1973; Salby and Garcia, 1987). Since the latter is $12 \mathrm{~km}$ in our calculations, waves of vertical wavelength $\sim 24 \mathrm{~km}$ are preferentially excited in the model troposphere. Upon entering the stratosphere, where the static stability roughly doubles with respect to that in the troposphere, the vertical wavelength is reduced to $\sim 12 \mathrm{~km}$.

Kelvin waves occur at phase speeds and zonal wavenum- 

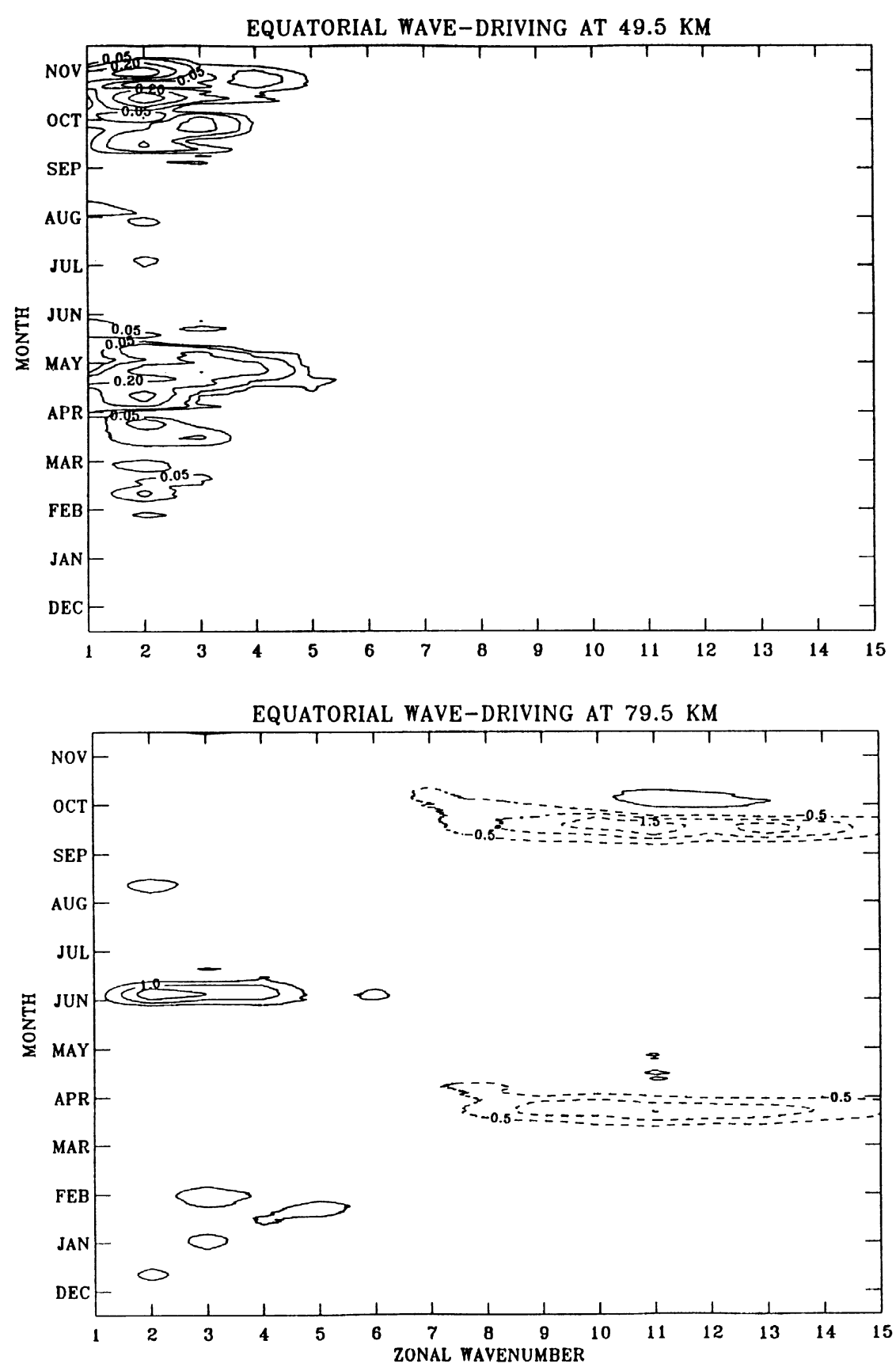

Fig. 2. Seasonal evolution of the zonal mean force $\left(\mathrm{m} \mathrm{s}^{-1}\right.$ day $\left.^{-1}\right)$ exerted by dissipating waves as a function of wavenumber, at $49.5 \mathrm{~km}$ and $89.5 \mathrm{~km}$. Westerly forces are due primarily to wavenumbers $k=1-6$ and are associated with Kelvin waves. Contributions from wavenumbers $k=7-15$ dominate the easterly forcing and are due to inertia-gravity waves excited by the diurnal cycle of convection.

bers related by the dispersion equation $c=N / m$, where $c$ is the intrinsic phase speed, $m$ is the vertical wavenumber, and $N$ is the buoyancy frequency. In the stratosphere, where $m \simeq 2 \pi / 12 \mathrm{~km}^{-1}$ and $N=0.02 \mathrm{sec}^{-1}$, this gives:

$$
c=\frac{N}{m}=38 \mathrm{~m} \mathrm{~s}^{-1}
$$

so Kelvin wave variance in the frequency-wavenumber plane is expected to lie along the line $\omega=k c$, with $c=38 \mathrm{~m} \mathrm{~s}^{-1}$.

Kelvin waves are also excited, albeit with decreasing amplitude, at higher frequencies and shorter wavelengths (which are still related according to $c=N / m$ ). Inertia-gravity waves occur mainly at what SG called "intermediate wavenumbers" ( $k=4-15$ in the model.) These waves are forced strongly by the diurnal variation in convection, and thus are concentrated near the diurnal period, with phase velocities that decrease as a function of wavenumber, $c= \pm \omega_{\mathrm{d}} / k$, where $\omega_{\mathrm{d}}$ is the diurnal frequency.

For the purpose of interpreting model results it should be borne in mind that immediately above the forcing region, where the background wind is weak, the intrinsic phase speeds of all of these waves are nearly identical to the "ground-based" phase speeds. Thus, we can think of the 
wave spectrum emerging from the troposphere as being centered about ground-based phase speeds of $c=38 \mathrm{~m} \mathrm{~s}^{-1}$ for Kelvin waves and $c= \pm \omega_{\mathrm{d}} / k$ for gravity waves. As the waves propagate upward and encounter stronger background winds, $\bar{u}$, they may be damped or absorbed, especially when their intrinsic phase speeds become small.

Figure 3 shows the wavenumber-frequency spectrum produced by the model at 30 and $60 \mathrm{~km}$ during equinox. The features just mentioned (Kelvin wave variance lying along a line of constant phase velocity and inertia-gravity wave variance concentrated near easterly and westerly diurnal periods) are evident. Note that, although Kelvin wave variance at $30 \mathrm{~km}$ occurs along the line of $c \simeq 38 \mathrm{~m} \mathrm{~s}^{-1}$, at $60 \mathrm{~km}$ the variance is concentrated along $c \simeq 54 \mathrm{~m} \mathrm{~s}^{-1}$. This shift of variance to higher frequencies with increasing altitude is a result of enhanced damping of the lower-frequency Kelvin waves as they propagate upwards (see, e.g., Holton, 1973; Hayashi et al., 1984; Garcia and Salby, 1987; Boville and Randel, 1992). The spectrum at $60 \mathrm{~km}$ also contains less westerly inertia-gravity wave variance at high wavenumbers than the spectrum at $30 \mathrm{~km}$. These shorter westerly waves have relatively slow phase speeds (e.g., $c=\omega_{\mathrm{d}} / k=35$

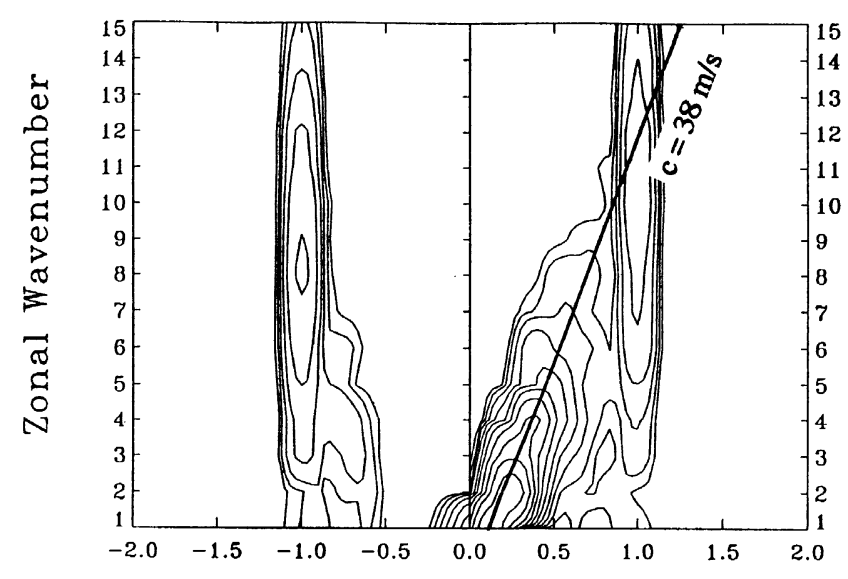

$\mathrm{z}=60 \mathrm{Km}$

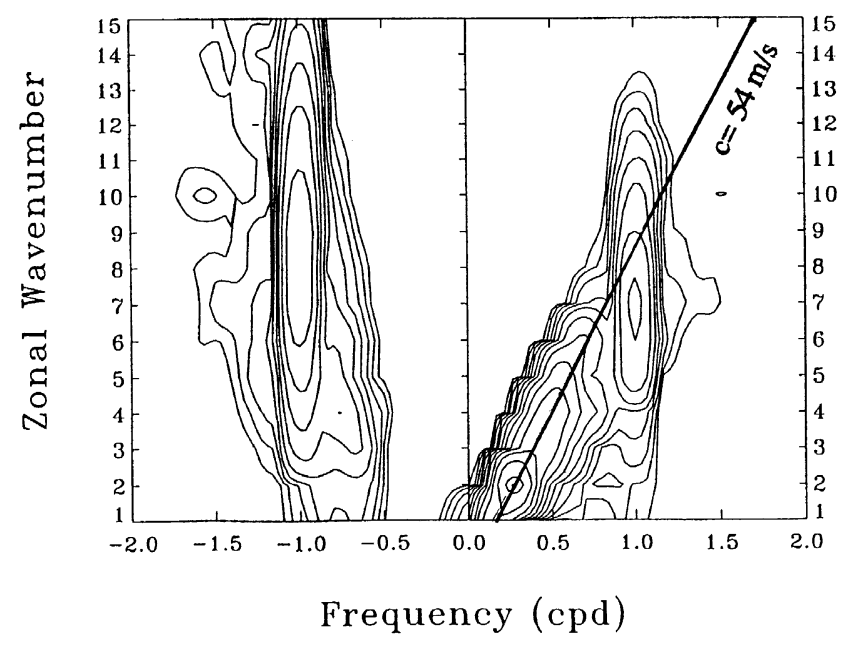

Fig. 3. Temperature power spectra at 30 and $60 \mathrm{~km}$ for the run of Fig. 1. Successive contour intervals each increase by a factor of 2 . $\mathrm{m} \mathrm{s}^{-1}$ at $k=13$ ) and are strongly damped or even absorbed in the descending westerly phase of the SAO (cf. Fig. 1).

Note, by the way, that the variance associated with the inertia-gravity waves at $\pm \omega_{\mathrm{d}}$ is significant even at the highest wavenumber $(k=15)$ included in the calculation. This indicates that the contribution of these waves to the SAO is, if anything, underestimated by our model (as can be inferred from Fig. 1, where wave driving at both stratopause and mesopause remains significant for wavenumbers up to $k=15)$.

Manzini and Hamilton (1993) have studied the excitation of equatorial waves in the SKYHI general circulation model. The wavenumber-frequency spectrum in the vicinity of the stratopause (their figure 10) resembles that obtained in our simple model, lending some confidence to the robustness of the convective excitation mechanism for tropical waves. Similar behavior was reported by Boville and Randel (1992, their figure 5) in spectra derived from the NCAR Community Climate Model.

\subsection{The influence of the QBO}

We discuss next the results of a simulation in which the zonal wind in the tropical lower stratosphere is relaxed to observed values. The zonal wind data were compiled by the Free University of Berlin and kindly supplied by Dr. Steve Pawson. In all other respects the model is identical to that discussed in the previous section.

Figure 4 shows the evolution of the zonal wind over 3.75 years when the QBO is present. Although the stratospheric SAO remains much the same as in Fig. 1, the easterly phase of the mesospheric SAO is now noticeably weaker when a deep layer of strong easterly winds is present in the stratosphere. Compare, for example, the two easterly phases of year 2 (when stratospheric winds are easterly and stronger than $-30 \mathrm{~m} \mathrm{~s}^{-1}$ ), with the first easterly phase of year 1 , or the second of year 3 (when the stratospheric winds are mostly westerly). During the first pair of easterly phases the strongest mesospheric zonal winds are about $-30 \mathrm{~m} \mathrm{~s}^{-1}$, while in the second pair they are between $-40 \mathrm{~m} \mathrm{~s}^{-1}$ and -50 $\mathrm{m} \mathrm{s}^{-1}$. Even so, these results underestimate the apparent effect of the QBO; in the observations, the contrast between easterly phases occurring during QBO westerlies and those occurring during QBO easterlies can be as large as a factor of two $\left(\sim-40 \mathrm{~m} \mathrm{~s}^{-1}\right.$ vs. $\sim-80 \mathrm{~m} \mathrm{~s}^{-1}$; see Garcia et al., 1997).

In the model, the difference in the strength of the mesopause easterly phases can be attributed to modulation of inertia-gravity wave activity reaching the mesosphere. Figure 5 compares wavenumber-frequency spectra in the lower mesosphere for the second easterly phase (October) of year 2 , when the stratospheric winds are strongly easterly, and the second easterly phase of year 3 , when they are predominantly westerly. It is immediately apparent that the variance associated with easterly inertia-gravity waves at $k \geq 11$ is much reduced when the stratospheric winds are easterly. Since these waves occur near the diurnal frequency, the phase velocity decreases with increasing wavenumber (from $\sim-41 \mathrm{~m} \mathrm{~s}^{-1}$ at $k=11$ to $\sim-23 \mathrm{~m} \mathrm{~s}^{-1}$ at $k=15$ ). Clearly, these waves have been damped strongly, or even absorbed, as they propagated through the easterly QBO winds in the stratosphere, which are stronger than $-30 \mathrm{~m} \mathrm{~s}^{-1}$ during year 2 . 


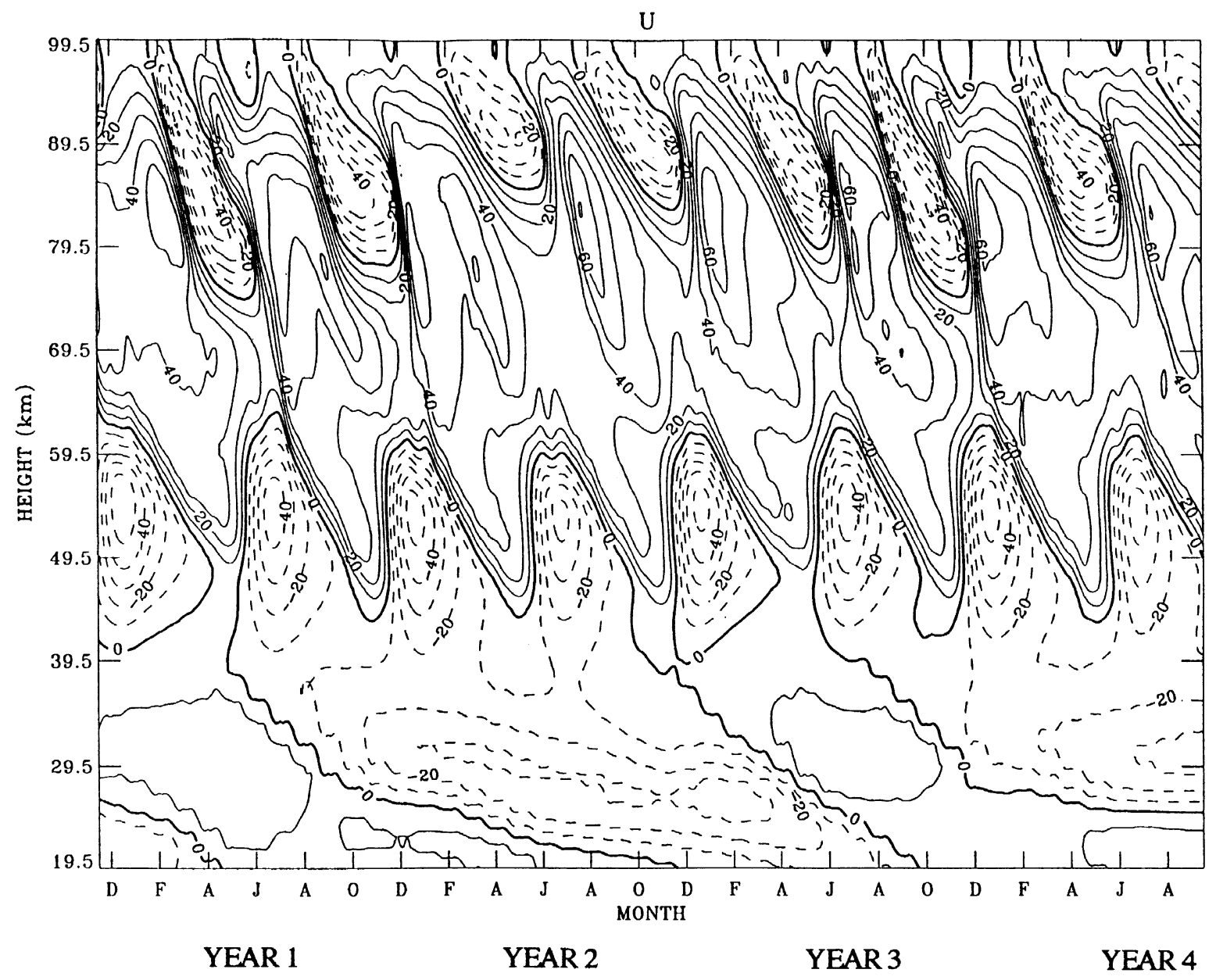

Fig. 4. The evolution of the zonal mean wind $\left(\mathrm{m} \mathrm{s}^{-1}\right)$ over 3.75 years in a run that includes the stratospheric QBO. Mesospheric easterly phases occurring when the QBO winds are easterly are substantially weaker than those occurring when the QBO winds are westerly.

Variance at other easterly wavenumbers is reduced much less dramatically. Nonetheless, the effect on wave driving of removing easterly waves of $k \geq 11$ is substantial because a large fraction of the zonal mean force during the easterly phase (Fig. 2) is provided by the shorter waves. As noted previously, the fact that wavenumbers up to and including the truncation limit of the model $(k=15)$ contribute significantly to the wave driving implies that our calculation underestimates the total effect of the shorter waves. Presumably, a calculation including wavenumbers up to $k=20-30$ would have produced an even greater contrast between mesospheric easterly phases, and brought the model into closer agreement with observations.

We have shown how the stratospheric wind QBO can modulate the strength of the easterly phase of the mesospheric SAO. Further inspection of Figs. 2 and 4 reveals why the westerly phase of the SAO is unaffected by the QBO. From Fig. 2, it is clear that westerly accelerations are provided mostly by waves of $k=1-6$ in both the stratosphere and mesosphere. But, as noted above, these are predominantly Kelvin waves with phase velocities of $\sim 38 \mathrm{~m} \mathrm{~s}^{-1}$ in the stratosphere and $\sim 54 \mathrm{~m} \mathrm{~s}^{-1}$ in the lower mesosphere, whereas the stratospheric zonal wind during the westerly phase of the
QBO is always less than $15 \mathrm{~m} \mathrm{~s}^{-1}$ (Fig. 4). Thus, the asymmetry between the phases of the zonal wind QBO, coupled with the fact that the waves that drive the SAO westerly phase are faster than those that drive the easterly phase, means that the QBO is capable of modulating only the easterly spectrum of vertically-propagating tropical waves.

\section{Discussion}

We have described a simple mechanism whereby the QBO in stratospheric zonal wind can modulate the easterly (but not the westerly) phase of the mesospheric SAO. The mechanism is apparently robust, insofar as the relevant waves are present both in our simple model and in general circulation model simulations such as those of Boville and Randel (1992), and Manzini and Hamilton (1993). Further, the excitation mechanism for the waves (deep convective heating) is also grounded in recent analyses of variability of tropical convection (Salby et al., 1991; Bergman and Salby, 1994).

It is likely, however, that the waves included in our model are not the whole story. As noted earlier, wavenumbers up to the truncation limit of the model $k=15$ make significant contributions to the SAO easterly phase in the mesosphere, so the overall influence of shorter waves is proba- 


\section{$\mathrm{z}=60 \mathrm{Km}$}
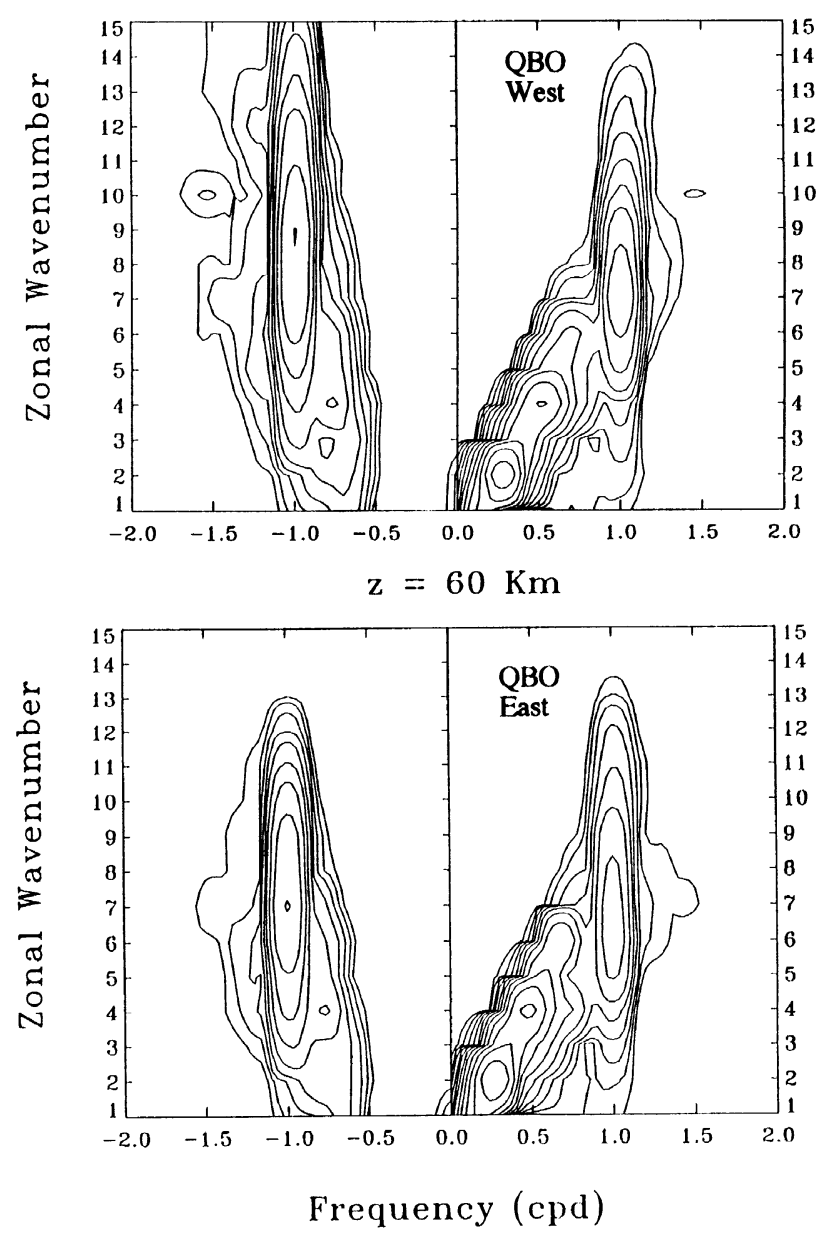

Fig. 5. Temperature power spectra at $60 \mathrm{~km}$ for the run of Fig. 4 during QBO easterlies (October of year 2) and QBO westerlies (October of year 3 ). Successive contour intervals increase by a factor of 2 . The spectrum of easterly waves during the QBO easterly phase has reduced power at $k=11-12$ and negligible power at $k=13-15$ relative to the spectrum during the QBO westerly phase.

bly underestimated in our calculations. Wavenumbers up to $k=20-30$ (zonal wavelengths $\simeq 1300-2000 \mathrm{~km}$ at the equator), and perhaps beyond, are also likely to contribute to the easterly zonal force in the mesosphere. Mayr et al. (1997), used a small-scale gravity wave parameterization to produce both semiannual and quasibiennial oscillations in a numerical model. The QBO in Mayr et al.'s model modulates the $\mathrm{SAO}$, although the effect $\left(\sim 10 \mathrm{~m} \mathrm{~s}^{-1}\right.$ peak-to-peak in the mesosphere) is weaker than observed.

This kind of ambiguity is present in much of the work on the SAO (and QBO): Although the oscillations are evidently caused by interactions between the mean flow and verticallypropagating waves, the nature of the waves and their excitation mechanisms remains in doubt. As regards the SAO, it is known only that planetary-scale $(k=1-3)$ Kelvin waves are not sufficient to drive the stratospheric easterly phase (Hitchman and Leovy, 1988); almost nothing is known about the waves responsible for producing the mesospheric SAO. In SG and in the present work, we have attempted to justify the role of planetary and intermediate-scale waves by forcing them with plausible estimates of unsteady convective heating, but observational confirmation of the existence of the faster, shorter waves produced in our model is lacking.

Unfortunately, synoptic observations of any but the largerscale (and slower) tropical waves do not exist. Polar-orbiting satellites are able to resolve unambiguosly wavenumbers $k \lesssim 6$ and periods $\gtrsim 2$ days. Ground-based observations (e.g., radars, radiosondes, etc.) have for all practical purposes arbitrarily high time resolution, but measurements from a single site provide neither a global view nor the ability to distinguish among different zonal scales. For example, Tsuda et al. (1994) have documented the presence of nonmigrating diurnal oscillations in radiosonde observations from Indonesia, but these data do not provide information about the synoptic structure of the oscillations. It may be that evaluation of the relative importance of the tropical waves considered in this study relative to small-scale gravity waves such as those considered by Mayr et al. (1997) may have to rely on further assessment of the excitation mechanisms for each. Alternatively, an ensemble of ground-based observing sites appropriately spaced in longitude and operating synchronoulsy could provide the necessary spatial and temporal resolution, at least along one latitude circle. However, the financial and logistical demands of long-term operation of such a system would appear to be prohibitive.

A further note of caution is appropriate in closing. Although the correlation between the mesospheric easterly phase and the stratospheric QBO is striking in HRDI wind observations, it is not always present in MF radar measurements from Christmas Island (see Garcia et al., 1997). During the period (1992-1995) for which both HRDI and radar observations are available, the two datasets show weak mesospheric SAO easterly phases when the QBO is easterly, and much stronger SAO easterly phases when the QBO is westerly. However, when the radar data for 1990-1991 are examined, the relationship fails to hold, especially in the the second SAO cycle of 1990, which was rather weak even though QBO winds were westerly at the time. In our model, on the other hand, the relationship between the QBO and the easterly phase of the mesospheric SAO holds uniformly. It is possible that in the real atmosphere interannual variability in wave forcing, which is not included in the model, can produce as large an effect as that due to the phase of the QBO winds in the stratosphere.

Acknowledgments. This research was supported in part by a grant from the National Aeronautics and Space Administration. We are grateful to Anne K. Smith, Bill Randel, and two anonymous reviewers for their comments on the original manuscript. The National Center for Atmospheric Research is sponsored by the National Science Foundation.

\section{References}

Andrews, D. G., J. R. Holton, and C. B. Leovy, Middle Atmosphere Dynamics, 489 pp., Academic Press Inc., 1987.

Bergman, J. W. and M. L. Salby, Equatorial wave activity generated by fluctuations in observed convection, J. Atmos. Sci., 51, 3791-3806, 1994.

Boville, B. A. and W. J. Randel, Equatorial waves in a stratospheric GCM: Effects of vertical resolution, J. Atmos. Sci., 49, 785-801, 1992.

Burrage, M. D., R. A. Vincent, H. G. Mayr, W. R. Skinner, N. F. Arnold, and P. B. Hays, Long term variability in the equatorial mesosphere and lower thermosphere zonal winds, J. Geophys. Res., 101, 12847-12854, 
1996.

Garcia, R. R. and M. L. Salby, Transient response to localized episodic heating in the tropics. Part II: Far-field behavior, J. Atmos. Sci., 44, 499-530, 1987.

Garcia, R. R., T. J. Dunkerton, R. S. Lieberman, and R. Vincent, Climatology of the semiannual oscillation of the tropical middle atmosphere, $J$. Geophys. Res., 102, 26019-26032, 1997.

Hayashi, Y., D. G. Golder, and J. D. Mahlman, Stratospheric and mesospheric Kelvin waves simulated by the GFDL "SKYHI" general circulation model, J. Atmos. Sci., 41, 1971-1984, 1984.

Hirota, I., Equatorial waves in the upper stratosphere and mesosphere in relation to the semiannual oscillation of the zonal mean wind, J. Atmos. Sci., 35, 714-722, 1978.

Hitchman, M. H. and C. B. Leovy, Estimation of the Kelvin wave contribution to the semiannual oscillation, J. Atmos. Sci., 45, 1462-1475, 1988.

Holton, J. R., Waves in the equatorial stratosphere generated by tropospheric heat sources, J. Atmos. Sci., 29, 368-375, 1972.

Holton, J. R., On the frequency distribution of atmospheric Kelvin waves, J. Atmos. Sci., 30, 499-501, 1973.

Manzini, E. and K. P. Hamilton, Middle atmospheric traveling waves forced by latent and convective heating, J. Atmos. Sci., 50, 2180-2200, 1993.

Mayr, H. G., J. G. Mengel, C. O. Hines, K. L. Chan, N. F. Arnold, and C. A.
Reddy, The gravity wave Doppler spread theory applied in a numerical spectral model of the middle atmosphere. 2. Equatorial oscillations, $J$. Geophys. Res., 102, 26093-26105, 1997.

Reed, R. J., Some features of the annual temperature regime in the tropical stratosphere, Mon. Weather Rev., 90, 211-215, 1962.

Reed, R. J., Zonal wind behavior in the equatorial stratosphere and lower mesosphere, J. Geophys. Res., 71, 4223-4233, 1966.

Salby, M. L. and R. R. Garcia, Transient response to localized episodic heating in the tropics. Part I: excitation and short-term near field behavior, J. Atmos. Sci., 44, 458-498, 1987.

Salby, M. L., H. H. Hendon, K. Woodberry, and K. Tanaka, Analysis of global cloud imageries from multiple satellites, Bull. Am. Meteor. Soc., 72, 467-480, 1991.

Sassi, F. and R. R. Garcia, The role of equatorial waves forced by convection in the tropical semiannual oscillation, J. Geophys. Res., 54, 1925-1942, 1997.

Tsuda, T., Y. Maruyama, H. Wiryosumarto, S. W. B. Harijono, and S. Kato, Radiosonde observations of equatorial atmosphere dynamics over Indonesia, 1, Equatorial waves and diurnal tides, J. Geophys. Res., 99, 10491-10506, 1994.

R. R. Garcia (e-mail: rgarcia@ncar.ucar.edu) and F. Sassi 